\title{
A UFMG na Mostra dos Estudantes da PQ19
}

\author{
Cristiano Cezarino Rodrigues \\ Universidade Federal de Minas Gerais - UFMG, Belo Horizonte/MG, Brasil \\ E-mail: cristianocenografo@gmail.com \\ Tereza Bruzzi De Carvalho \\ Universidade Federal de Minas Gerais - UFMG, Belo Horizonte/MG, Brasil \\ E-mail: tbruzzi@ufmg.br \\ Maria Laura de Vilhena Dias e Silva \\ Universidade Federal de Minas Gerais - UFMG, Belo Horizonte/MG, Brasil \\ E-mail: marialauradevilhena@gmail.com
}

\section{Resumo}

O presente trabalho aborda a experiência de participação da Universidade Federal de Minas Gerais - UFMG na representação do Brasil na Mostra dos Estudantes na Quadrienal de Praga em 2019. Relata o processo de concepção, idealização, realização e participação do trabalho desenvolvido pelos alunos no âmbito da disciplina Cenografia, na Formação Transversal em Processos Criativos e Culturas em Movimento da UFMG. A partir desse relato, busca-se compreender o ensino da Cenografia na UFMG e sua relação com o grupo de pesquisa Barracão, que, nos últimos anos, se tornou referência no assunto nessa instituição. Por fim, discute-se as relações e a repercussão que a $P Q$ estabelece nas proposições sobre a cenografia no que tange ao ensino, à pesquisa e à extensão na UFMG.

\section{Palavras-chave}

Cenografia. Quadrienal de Praga. Ensino.

Pesquisa. Extensão universitária. UFMG.
This paper discusses the experience of Federal University of Minas Gerais - UFMG participations in the Prague Quadrennial Student Show in 2019, representing Brazil. It reports the process of conception, idealization, accomplishment and participation of the work developed by the students in the context of Scenography Discipline, at UFMG's Cross Training in Creative Processes and Cultures in Motion. From this report, we seek to understand the teaching of scenography at UFMG and its relationship with the research group Barracão, which in recent years has become a reference in the subject at this institution. Finally, we discuss the relationships and repercussions that $P Q$ establishes in the scenography propositions regarding teaching, research and extension at UFMG.

Keywords

Scenography. Prague Quadrennial. Teaching.

Research. Extension. UFMG. 


\section{Introdução}

A provocação feita pela equipe responsável pelo dossiê da revista Cena - Quadrienal de Praga: Espaço e Desenho da Cena - motivou-nos a registrar as experiências de participação da Universidade Federal de Minas Gerais - UFMG no evento e, consequentemente, a analisar alguns aspectos da Cenografia enquanto campo do conhecimento acadêmico na universidade. A UFMG participou com trabalhos que compuseram o acervo da exposição que representou o Brasil na Mostra dos Estudantes nas edições de $2015^{1}$ e $2019^{2}$ da Quadrienal de Praga ${ }^{3}$ (PQ). $\mathrm{Em}$ ambas as edições, os trabalhos apresentados tinham em comum experiências que abordavam os três pilares que constituem a Universidade, ou seja, ensino, pesquisa e extensão ${ }^{4}$ em diferentes aspectos.

A fim de sistematizar as experiências da UFMG na Quadrienal de Praga, julgamos relevante, em um primeiro momento, contextualizar essa proposta no âmbito da UFMG, entendendo como ela se torna viável dentro de um trabalho desenvolvido por um grupo de professores e pesquisadores em Cenografia já há algum tempo em diferentes unidades da instituição. Na sequência, descreveremos o processo de concepção e desenvolvimento do trabalho que foi para Praga. Posteriormente, passaremos à discussão de que tipo de relação a $P Q$ estabelece com essas práticas acadêmicas e qual a sua influência e repercussão, tentando entendê-la dentro de seu processo de mudança conceitual que se dá mais enfaticamente a partir da edição de

\footnotetext{
1 Para maiores informações sobre a mostra, ver PAIVA, 2015 e visitar: <https://brasillabirintoscompartilhados.wordpress.com/>.

2 Para maiores informações sobre a mostra, ver MONTEIRO, 2019 e visitar: <https://pqbrasil.org/>.

3 The Prague Quadrennial of Performance Design and Space - PQ. Para maiores informações sobre o evento, tais como proposta curatorial, organização, programação etc, ao longo dos anos, visitar: <http://www.pq.cz/>.

4 Os trabalhos apresentados saem da experiência de sala de aula, se tornam pesquisas e culminam na execução dos cenários em uma atividade fora da comunidade escolar.
}

2011. Por fim, analisamos esta trajetória de participações dos trabalhos da UFMG na $P Q$ tendo como referência a edição de 2019 e seus desdobramentos imediatos no ensino, na pesquisa e na extensão universitárias no contexto desta Universidade.

\section{O Barracão UFMG 5}

Em 2014 é criado o Barracão UFMG - Núcleo de Pesquisa em Cenografia e outras práticas cênico-performáticas. Composto pelos professores Cristiano Cezarino (Escola de Arquitetura), Ed Andrade (Teatro) e Tereza Bruzzi (Teatro Universitário), este núcleo ainda se desdobraria em atividades além da pesquisa, operando também no ensino e na extensão universitária. Os três professores iniciaram um experimento pedagógico ao propor um formato alternativo para a disciplina Cenografia, que compõe o currículo regular do curso de Teatro, ou seja, era normalmente cursada estritamente por alunos deste curso.

A proposta foi abrir a disciplina para outros cursos além do Teatro, como Arquitetura, Artes Visuais e outros, entendendo a natureza da cenografia em seu caráter transdisciplinar. Desse modo, antecipam o que ocorreria em seguida na UFMG com a criação das formações transversais ${ }^{6}$,

5 O Barracão atualmente é um grupo de pesquisa certificado pelo CNPQ: Barracão - Núcleo de Pesquisa e Experimentação em Cenografia e outras práticas espaciais cênico-performáticas. Para maiores informações, ver <http://dgp.cnpq.br/dgp/espeIhogrupo/41531> e http://www.arq.ufmg.br/site/v2/extensao/ projetos-de-extensao/barracao-concepcao-e-producao-de-cenografias-no-ambito-da-ufmg/. (DIRETÓRIO DOS GRUPOS DE PESQUISA NO BRASIL, 2019).

6 As Formações Transversais são conjuntos de atividades acadêmicas curriculares, organizadas segundo estruturas curriculares, que visam abordar temáticas de interesse geral, incentivando a formação de espírito crítico e de visão aprofundada sobre esses temas. O sistema de Formações Transversais constitui um espaço comum de formação para os estudantes de todos os cursos de graduação da UFMG. Para maiores informações: $<$ https://www2.ufmg.br/prograd/prograd/Pro-Reitoria-de-Graduacao/Estudante/Formacao-Transversal>. 
das quais a disciplina Cenografia ${ }^{7}$ viria a fazer parte. Assim, um professor da Escola de Belas Artes, outro da Escola de Arquitetura e uma professora do Teatro Universitário ministram juntos a disciplina que foi norteada em três eixos: o didático-pedagógico, que se constitui de procedimentos didáticos de ensino em sala de aula, onde são abordados alguns pressupostos teóricos, práticos e técnicos do campo da cenografia; o prático-experimental, que se constitui de estágios temporários, nos quais os alunos fariam o acompanhamento, registro e documentação de processos de criação cenográfica junto a montagens profissionais de espetáculos produzidos em Belo Horizonte; e o eixo teórico-conceitual, que se constitui da análise e reflexão teórica dos processos de criação documentados, a partir de conceitos propostos.

Um dos principais desdobramentos da disciplina foi a produção de material de exposição para a participação dos discentes na Mostra Brasil: Labirintos Compartilhados - Mostra dos Estudantes Brasileiros de Cenografia na Quadrienal de Praga do Desenho e Espaço da Performance em 2015. Sendo assim, em 2015, dois dos três projetos encaminhados à Mostra Brasileira de Cenografia foram selecionados para compor o acervo da mostra em Praga.

Além disso, o núcleo de pesquisa pretendia promover o envolvimento dos alunos com processos de criação de cenografia para grupos profissionais de Belo Horizonte que serviram como objeto de investigação e análise, colocando-os em

\footnotetext{
7 A disciplina Cenografia é semestral e é ofertada anualmente na Formação Transversal em Culturas em Movimento e Processos Criativos com uma carga horária de $60 \mathrm{~h}$. Tem como ementa descritiva na versão para 2020/1: "Parte-se da noção de que o design da performance e a cenografia situam-se numa zona fronteiriça entre diferentes campos do saber, abarcando práticas e pensamentos oriundos da arquitetura, das artes visuais e do teatro, apresentando-se, portanto, como uma disciplina de natureza híbrida e fundamentalmente transversal. A disciplina promoverá experimentos práticos e críticos sobre o design da performance e da cenografia, buscando introduzir noções básicas do processo de concepção e produção do espaço cênico e abordagem de aspectos técnicos, práticos e teóricos referentes ao campo da cenografia e do design da performance, bem como o conhecimento das funções e possibilidades da cenografia na constituição do discurso cênico contemporâneo".
}

contato diretamente com o mercado profissional. $\mathrm{O}$ que acarretou, posteriormente, na inserção desses alunos no campo profissional de modo significativo.

Se em 2015 a realidade do grupo que se iniciava anunciava uma grande conexão com a Quadrienal de Praga tanto na lógica dos processos criativos como nos conceitos, em 2019 essa realidade se torna ainda mais forte. O que vimos, ao longo desses anos, foi que apesar de grande parte do processo de aprendizado em cenografia se dar através da relação mestre/aprendiz (ofício), o pensamento reflexivo que vai além da técnica e da observação compositiva é fundamental para a transformação da mesma em campo de conhecimento acadêmico dentro da Universidade. Nesse sentido, pelo caráter muito recente em todo o mundo, mas principalmente em Belo Horizonte, os nossos questionamentos têm sido muito acolhidos não apenas no evento das Quadrienais, mas também nas publicações e eventos por ela gerados.

A UFMG na PQ2019

Um dos trabalhos que compôs a representação brasileira na Mostra dos Estudantes na PQ19 foi a exposição do cenário e da iluminação dos espetáculos de formatura dos alunos do Teatro Universitário de 2017: Os Negros e A Cerimônia. Como visto, a aproximação do Barracão com a produção do TU tornou-se um espaço frutífero para o desenvolvimento de trabalhos práticos, estabelecendo uma relação efetiva entre ensino e extensão. Ao longo do semestre da disciplina Cenografia, na Formação Transversal em Processos Criativos e Culturas em Movimento, os estudantes tomaram conhecimento do tema, dos textos e das demandas pautadas pela direção teatral da montagem de formatura. O exercício prático da disciplina foi a proposta de uma cenografia amparada tanto pelos encontros semanais de $4 \mathrm{~h}$, próprios da disciplina, quanto pelos encontros extracurriculares (com o elenco e a equipe técnica da montagem), auxiliando os alunos na instrumenta- 
ção da tarefa. Isso era fundamental, pois, no âmbito da Formação Transversal, as disciplinas são cursadas por estudantes de diversos cursos e campos que, em vários casos, não possuem uma relação afim com o tema central da disciplina (cenografia e design da performance). A turma se dividiu em grupos e, como estratégia didática, demandou-se que os mesmos fossem diversos, contemplando cursos diferentes, no intuito de promover uma integração de saberes e capacidades mais natural e orgânica. Os alunos conceberam as primeiras ideias, ao longo das discussões em sala e das orientações dos professores Cristiano Cezarino e Tereza Bruzzi na condução dos trabalhos, descartaram e substituíram algumas proposições, amadurecendo as ideias à medida que estas se complexificavam. No fim do processo, tínhamos algumas propostas de cenário que contemplavam aspectos técnicos essenciais como técnicas construtivas, materiais, modos de montagem, bem como aspectos cênicos em que se vislumbrava o uso do cenário ao longo da apresentação.

A montagem de Os Negros e A Cerimônia possuía características peculiares que estabeleciam critérios que definiam fundamentalmente as propostas de cenografia. Em razão da constatação de que a turma de formatura do Teatro Universitário seria composta em sua metade por alunos(as) negros(as), pela primeira vez, o diretor teatral, Rogério Lopes, escolheu registrar essa conquista para a comunidade, separando a turma em dois elencos. O primeiro deles, composto por alunos(as) negros(as) encenou o espetáculo Os Negros, adaptado do texto de Jean Genet Os Negros: uma clowneria. Já a segunda metade da turma se envolveria com o espetáculo $A C e-$ rimônia, uma adaptação do texto Cerimônia para um negro assassinado, de Fernando Arrabal. De formas distintas, ambos os textos abordavam a questão das desigualdades raciais e sociais existentes como tema central, sendo apresentados sequencialmente em um mesmo dia. Para tanto, as propostas para a cenografia deveriam contemplar uma solução que pudesse atender aos dois textos, sem o acréscimo de muitos elementos cênicos novos. Nesse sentido, as propostas buscaram desenvolver elementos que fossem versáteis e mutáveis, que se transformassem a cada encenação, mas que preservassem uma linguagem visual unificada do trabalho e do tema central.

Outra demanda apresentada pela direção foi a de ocupação cenográfica em um espaço teatral alternativo, um dos galpões da antiga Rede Ferroviária Federal S.A., que atualmente compõe as locações da Funarte BH. O galpão, que recebeu a montagem de formatura do TU durante duas semanas, foi adaptado para transformar-se em teatro, com varas fixas para iluminação e cenografia, oferecendo certo grau de liberdade para a construção do arranjo de palco e plateia. Assim, os alunos puderam experimentar diferentes relações espaciais entre atores e espectadores e como isso poderia repercutir nos espaços cênico e teatral. As propostas dos alunos apresentaram diversas soluções de arranjos espaciais e é notável como a integração entre esses com as propostas de cenografia eram intrinsecamente orgânicas, o que demonstra um entendimento dos alunos em relação às questões contemporâneas da cenografia e da produção do espaço teatral.

Ao fim da disciplina de Cenografia, os alunos participantes foram convidados a apresentar as propostas para a turma e para o diretor teatral, desde o processo até o resultado final, deixando evidente os elementos textuais e imagéticos que orientaram o trabalho. Com esse exercício foi possível perceber como cada grupo, com suas experiências e interpretações próprias, estabeleceu a transformação do espaço e também quais dessas propostas se alinhavam mais com a visão do diretor e dos elencos sobre a montagem. Dentre os participantes da disciplina, duas alunas Maria Laura de Vilhena Dias e Laysla Silva de Araújo Dias foram convidadas a continuar o trabalho junto aos elencos e ao corpo técnico do Teatro Universitário, acompanhando os ensaios e discussões e compondo a equipe de cenografia do espetáculo. A vivência semanal com a equipe exigiu alterações na proposta inicial que, comunican- 
do-se com os critérios estabelecidos previamente e os textos de origem de modo a reforçar alguns conceitos e sensações por meio da espacialidade, levaram ao desenvolvimento de uma proposta final.

Em um primeiro momento, destacou-se os contrastes bem marcados entre os mundos de cada uma das peças, representados pela disposição espacial dos elementos em cena. Em Os Negros, os praticáveis móveis criados pela equipe são utilizados para compor uma hierarquia entre os personagens, compondo dois espaços distintos: o da corte e o dos negros. A corte de pele branca se assenta sobre os praticáveis, cada qual com uma altura diferente de modo a representar as relações de poder internas ao próprio grupo e apenas no mais alto deles há um trono para a rainha branca. Esses praticáveis também foram dispostos de modo a formar uma arquibancada enquadrada por uma exuberante cortina austríaca dourada, trazendo à cena um clima de cabaré e ao mesmo tempo apresentando a teatralidade dos poderes. Por sua vez, os negros se encontram livres para percorrer a área cênica e as relações de poder internas são muito menos explícitas. Ainda assim era possível perceber figuras de liderança, sendo que a maior delas, a personagem Felicidade, ocupava um trono idêntico àquele onde se senta a rainha branca, na mesma altura em que está a corte.

Figura 1 - Cena Geral de Os Negros.

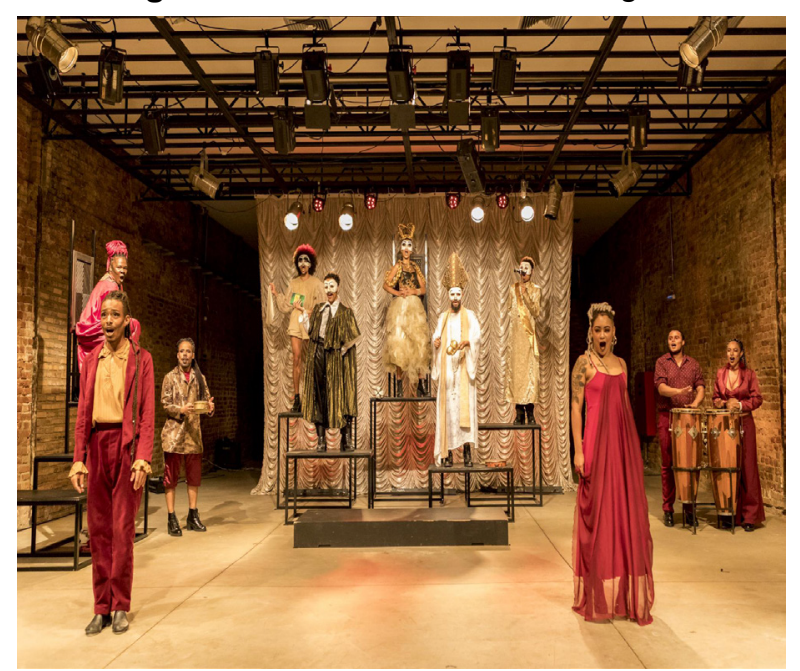

Fonte: Fotografia por Eduardo (Du) Santos.
No caso de A Cerimônia, os mesmos praticáveis assumiram uma conformação mais labiríntica, configurando o lar inóspito e caótico em que os personagens habitam. Somado aos praticáveis incorporou-se outros elementos: um armário, que é ressignificado ao longo da peça como uma porta, um confessionário ou um palco; uma banheira, assumindo a função de cama, esconderijo, sofá, baú etc.; a cabeceira que enquadra a banheira, feita com os tronos das duas rainhas em Os Negros; além dessas há duas camas em cena, que podem ser encaixadas, formando um só objeto, um só corpo. Um outro recurso que evidencia as diferenças entre as duas peças foi obtido por meio da iluminação. Em Os Negros há um predomínio de cores quentes, principalmente o vermelho, endossando, junto ao figurino, o glamour desse universo do cabaré. Já em A Cerimônia predomina o tom lavanda, trazendo a sensação de vilanismo, mistério, sombra, suspense.

Figura 2 - Cena Geral de A Cerimônia.

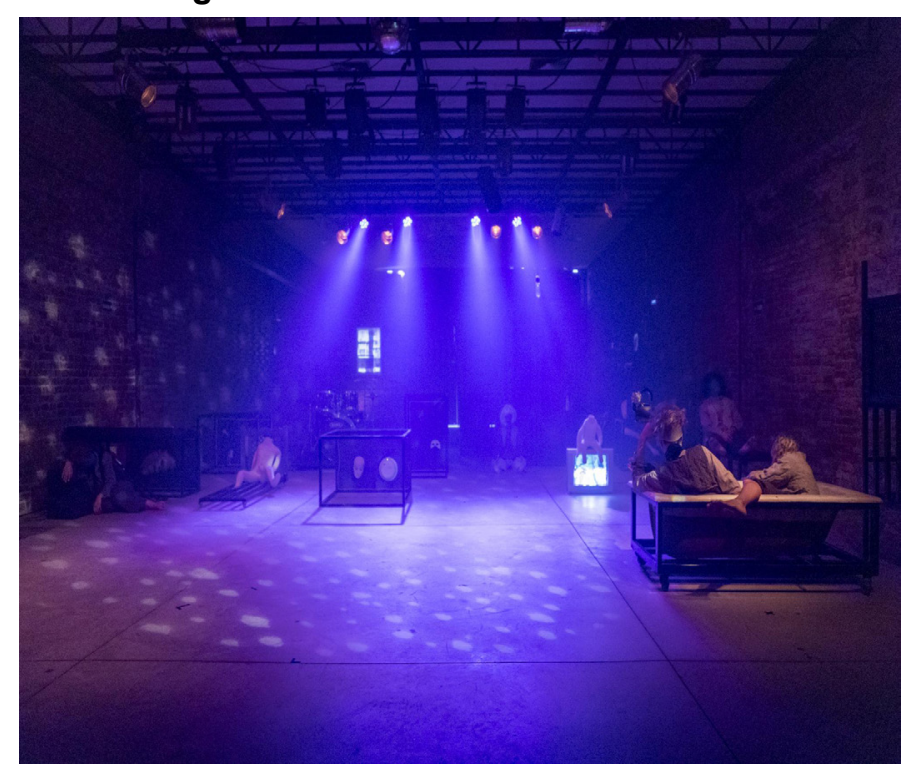

Fonte: Fotografia por Eduardo (Du) Santos.

$O$ arranjo entre palco e plateia também foi alterado ao longo do processo. Durante a disciplina, a proposta desenvolvida pelas duas alunas trabaIhava essa relação como semiarena. No entanto, ao acompanhar os ensaios, a relação frontal das duas peças ganhou força, o que levou à utilização da ar- 
quibancada para acomodar a plateia. O recurso da arquibancada também permitiu um espelhamento entre a cena e o espectador, suprindo a necessidade dos dois textos de identificação com o tema e reconhecimento das hierarquias e opressões raciais e sociais por parte da plateia. Por fim, o projeto final desenvolveu uma linguagem visual comum às duas montagens, em que a maioria dos elementos cênicos partia da estrutura aparente, tal qual um esqueleto, evidenciando a ideia de que as desigualdades raciais e sociais representadas por ambas as peças seriam estruturais, intensas e demarcadas.

Após a estreia das montagens na Funarte no final de 2017, a equipe de cenografia e de iluminação, tendo se aproximado durante o processo, se reuniu novamente no início de 2018 para sistematizar esse projeto de cenografia e iluminação desenvolvido para as duas montagens e inscrevê-lo na Mostra dos Estudantes da PQ19, representando o Brasili ${ }^{8}$. A comissão brasileira exigia que os trabalhos enviados tivessem as dimensões máximas de $36 \times 27 \times 18 \mathrm{~cm}$ com peso máximo de $2 \mathrm{~kg}$ (contando com a caixa de transporte), portanto, a impossibilidade de envio do cenário (que, além disso, permanecia em uso pelo elenco em diferentes festivais) nos levou a um processo de representação, além da sistematização escrita da proposta.

Primeiramente pensou-se em representar o cenário em forma de maquete, a fim de que os participantes da mostra pudessem construir o espetáculo em miniatura. No entanto, o incômodo com a literalidade na representação, a fragilidade dos elementos e a dificuldade de estruturar a luz na maquete nos levou a desenvolver uma representação mais sólida, que demonstrasse os elementos cênicos e a liga-

8 A comissão brasileira criou um edital para as inscrições de trabalhos em três categorias diferentes que contemplavam a Mostra dos Estudantes, sendo elas: EXPO[forma]AÇÃO, que abordaria os trabalhos e projetos das diversas áreas do desenho da performance; [fala]AÇÃO, que focaria nas discussões metodológicas e técnicas, e ESPAÇO[ex]POSITIVO, em que seria proposta uma ocupação expositiva para o espaço da $P Q$. Mais informações podem ser consultadas no site da PQ: <https://pqbrasil.org/mostradosestudantes>. ção entre as duas montagens. Partiu-se da lógica do cubo infinito em referência a uma das imagens que orientaram o trabalho durante a disciplina, por entender que este objeto interativo partia da transformação e ressignificação constante dos elementos, assim como a proposta de cenário desenvolvida. $\mathrm{O}$ objeto foi pensado, então, para representar as cenas e os elementos cenográficos em transformação, de um espetáculo para o outro e ao longo das peças. As imagens em cada face do cubo eram formadas por linhas simples, remetendo à estrutura vazada proposta como linguagem visual do espetáculo. Também enviamos junto ao objeto uma foto referente à cada cena representada no cubo, com as explicações técnicas e conceituais da cenografia e iluminação em seu verso, escritas em português e inglês.

Figura 3 - Objeto desenvolvido para a Mostra dos Estu-

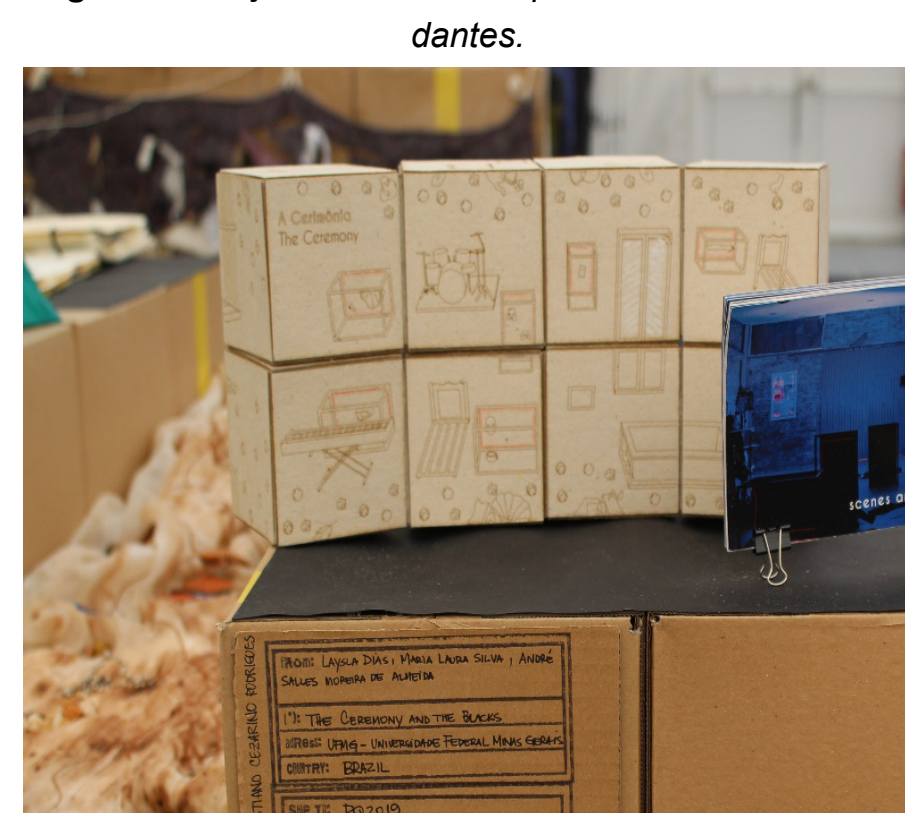

Fonte: Fotografia por Maria Laura de Vilhena.

O objeto desenvolvido foi enviado ao evento "IMAGINA[trans]forma[inter]ação", criado pela comissão brasileira, que buscou tanto selecionar os trabalhos para a Mostra dos Estudantes quanto promover um intercâmbio entre os diversos projetos e pesquisas nas áreas de cenografia e desenho do espaço da performance. O encontro, realizado em outubro de 2018 no Rio de Janeiro, contou com ro- 
das de conversas e debates além da apresentação e seleção dos trabalhos expostos no último andar do Centro Municipal de Arte Hélio Oiticica. Cabe ressaltar a predominância e certo grau de centralização dos debates e dos trabalhos no eixo Rio de Janeiro-São Paulo, representando mais da metade da exposição, um forte contraste em relação aos 3 trabalhos mineiros. Além disso, dos 16 trabalhos selecionados da categoria EXPO[forma]AÇÃO (sob a qual o projeto enviado foi inscrito) para representar o Brasil na Quadrienal de Praga, 14 foram produzidos por estudantes da região Sudeste, sendo 9 destes trabalhos produzidos no Rio de Janeiro. Esse aspecto significativo da Mostra nos provoca alguns questionamentos: onde estão os outros trabalhos estudantis de cenografia e desenho da performance no resto do país? Por que não conseguimos acessar as outras realidades e experiências teatrais? Estaríamos representando o Brasil, em sua dimensão continental, ou apenas a região Sudeste? Apesar das críticas, a postura da comissão brasileira se destaca na Quadrienal de Praga porque consegue apresentar múltiplas produções, ao invés de dar preferência a uma narrativa única sobre a cenografia e o desenho da performance no país. Dessa forma, o encontro e o intercâmbio de experiências e soluções cenográficas também se tornou mais rico.

\section{_ A PQ a cenografia enquanto campo de conhecimento}

Se dentro da UFMG, tanto no campo de pesquisa como na extensão, sentimos muito a importância do entendimento da Cenografia como disciplina e não como ofício, o diálogo dos integrantes do Barracão UFMG com a produção intelectual da PQs, seja por participação no evento, ou por publicações e outros meios de divulgação do conhecimento, tem tido um papel norteador importante. Para o grupo de pesquisa em questão, a $P Q$ tem sido compreendida como uma oportunidade singular de desenvolvimento de atividades diversas no que tange ao ensino, à pesquisa e à extensão. As questões pautadas pela linha curatorial do evento sempre captam aspectos ligados à cenografia e ao design da performance que se constituem pontos de discussão profícuos para aqueles que se envolvem com a pesquisa sobre o tema. O que observamos ao longo dessas experiências pedagógicas ${ }^{9}$ é que as pautas apresentadas pela $P Q$ encontram reverberação em um contexto bastante diferente daquele em que elas são originalmente fomentadas, sobretudo pela curadoria do evento, que muda em cada edição. Nas duas edições em que os trabalhos dos estudantes da UFMG participaram as propostas já eram concebidas tendo as questões da PQ incorporadas aos parâmetros de definição dos enunciados dos trabalhos práticos realizados na disciplina Cenografia, ou seja, a problematização, a ideação e a realização tinham a $P Q$ como um horizonte e uma perspectiva a ser buscada.

Essa relação com as ditas pautas da $P Q$ não se deu somente nos trabalhos que antecedem as edições do evento, mas podemos perceber, ao fazer essa retrospectiva, que a experiência na Quadrienal influencia os trabalhos que sucedem as edições. Talvez o caso mais representativo seja o do ano de 2019, em que há uma nítida abertura no formato da apresentação dos trabalhos práticos finais da disciplina Cenografia. A cenografia no seu sentido clássico ligado ao Teatro começa a dar espaço para outras experiências, tais como a performance e a instalação, ampliando seu campo e aproximando-se ainda mais da noção de performance design. Nesse sentido, percebemos esses momentos enquanto importantes oportunidades para a discussão de um conceito que ainda se encontra em construção. Esses experimentos pedagógicos em que se constituem os trabalhos práticos da disciplina Cenografia buscam discutir na prática quais as implicações relativas a essa ideia de design da performance se a colocarmos em relação à noção de cenografia recorrente no Brasil (COHEN, 2007)

9 A saber, a participação na mostra dos estudantes nas edições de 2015 e na de 2019 , esta relatada no presente artigo. 
que se vincula predominantemente ao teatro dentro de uma estrutura arquitetônica de palco italiano.

Natalie Rewa (2012a), em seu texto sobre a $P Q$, afirma que a partir de 2011 amplia-se de forma considerável a experimentação na cenografia, o que faz esse campo do conhecimento se tornar mais visível. Em 2011, quando a PQ entra na cena de mostras internacionais, se estabelece uma crítica específica sobre o design na cenografia, que a coloca como um elemento central na produção teatral, havendo um deslocamento do conceito da cenografia para o design da performance.

Esse entendimento amplia de maneira significativa a noção da cenografia. Soma-se a isto o fato de que o nome da $P Q$ reflete um novo vocabulário profissional que passa por Design Teatral e Arquitetura, posteriormente por Design de Palco e Arquitetura Teatral, até a Cenografia e Arquitetura teatral. Recentemente, a nomenclatura adotada pela organização da PQ é Design da Performance e Espaço. Para Rewa (2012b), essa última nomenclatura tira a noção do design como uma prática descritiva e se engaja com a noção da performatividade mais afinada à interdisciplinaridade contemporânea. Assim, a Quadrienal, em constante mudança e tendo seus conceitos revisados pela curadoria e organização, acompanha também as questões vivenciadas na prática do fazer do design da performance.

Prǐhodová, McKinney e Lotker (2016) afirmam que a $P Q$ historicamente esteve centrada na noção de cenografia vinculada quase que exclusivamente a uma prática teatral. Nas edições da $P Q$ realizadas no início do milênio, a autora aponta uma progressiva mudança nessa noção, a qual ela afirma ser fruto de uma abertura do evento para participantes cujas práticas artísticas ultrapassam os modos tradicionais de se fazer teatro. Além disso, a ampliação dos editais para um grupo maior de países possibilitou um incremento das trocas culturais, abrindo ainda mais o espectro de possibilidades do que poderia ser definido como cenografia. À medida que presenciamos na $P Q$ a noção de uma cenografia teatral específica deixar o protagonismo, percebemos uma mudança no próprio evento em si. Onde via-se uma exibição de artefatos, agora se vê, cada vez mais, o seu processo de produção.

$P Q$ tem sido historicamente centrada em torno da "cenografia", como um tipo particular e exclusivo de prática de teatro que se concentra em maneiras de articular o espaço do palco. Esse tipo de prática, no entanto, cresce a partir de um conjunto específico de normas estéticas e expectativas culturais e também é condicionada por tipos particulares de instituições, de modelos econômicos e de sistemas políticos. (...) Ao expandir o conceito de cenografia para além do palco e reconceituar o ato de ver a cenografia em um espaço compartilhado, o tema deixa emergir elementos artísticos dentro da criação e introduz chamadas internacionais abertas para convidar artistas de várias disciplinas, pesquisadores, professores, estudantes - simplesmente qualquer pessoa interessada - para participar do tema. Em projetos interdisciplinares conduzidos, a $P Q$ abriu portas a participantes cujas práticas performáticas e formas de fazer teatro excederam a visão bastante limitada da "cenografia" como anteriormente entendida. (PŘíHODOVÁ; MCKINNEY; LOTKER, 2016, p. 05. Nossa tradução) ${ }^{10}$.

$10 P Q$ has been historically centred around "scenography", as a particular, rather exclusive type of theatre practice that focuses on ways to articulate stage space. This type of practice, however, grows from a specific set of aesthetic norms and cultural expectations and is also conditioned by particular types of institutions, economic models and political systems. (...) By expanding the concept of "scenography" beyond the stage and reconceptualizing the act of seeing scenography into sharing space, by moving away from displaying artefacts into creating them, and by introducing international open calls to invite artists across disciplines, researchers, teachers, students - simply anyone interested - to join in the interdisciplinary theme-driven projects, $P Q$ has opened doors to participants whose performative practices and ways of making theatre have exceeded the rather limited view of "scenography" as previously 
Příhodová, McKinney e Lotker (2016) acrescentam que as mudanças na noção de cenografia, que repercutiram e ainda repercutem na $P Q$, coincidem com a compreensão de que o cenário não é mais algo que está vinculado exclusivamente ao palco e ilustra um texto dramático. Ele pode surgir de um contexto urbano, de espaços ordinários do cotidiano e ainda pode relacionar-se a contextos e realidades diversas, seja do ponto de vista político, social ou identitário. Nesse sentido, outras práticas espaciais começam a ocupar lugares na PQ. Maquetes, fotos e registros de espetáculos realizados anteriormente vão cedendo espaço para performances ao vivo e experimentos que revelam cada vez mais a presença de falas, práticas, olhares e entendimentos diversos em torno do fazer e do pensar a cenografia. Assim, Př́hodová, McKinney e Lotker (2016, p. 08) pondera que é necessário para a $P Q$ :

No entanto, não devemos assumir que um processo de compartilhamento e aprendizado entre si seja uma questão simples ou direta; mesmo que parecesse ser expressa como tal no catálogo de 1975, está claro agora que a escala e o alcance do $P Q$ significa que ela não pode (e não deve) esperar trazer uma visão homogênea do design da performance ou de uma única comunidade de prática. Existe (e precisa haver) debate, desafio e desacordo sobre onde os limites do design devem ser traçados e quais são os principais valores e princípios das práticas nele contidas. As diferentes perspectivas que os participantes trazem para esses debates são informadas por conjuntos surpreendentemente diferentes de preocupações decorrentes de condições sociais, culturais e políticas específicas. Em uma inspeção mais detaIhada, $O P Q$ demonstra que não podemos pensar em uma comunidade singular de práti-

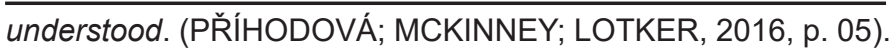

ca, mas em muitas comunidades que se cruzam. ((PŘíHODOVÁ; MCKINNEY; LOTKER, 2016, p.08). Nossa tradução). ${ }^{11}$

Essas mudanças que se processam na $P Q$ evidenciam ainda mais a complexidade intrínseca ao campo da cenografia. No contexto das práticas, dos pensamentos e do ensino da Cenografia no Brasil, cabe ressaltar que essas mudanças da $P Q$ também são sentidas. A noção de performance design influencia positivamente as equipes curatoriais responsáveis pelas representações do Brasil e percebe-se uma abertura maior para outros tipos de experimentos para além da produção cenográfica para o teatro. Como coloca Rosane Muniz Rocha (2016) ao descrever a trajetória histórica da $P Q$ em relação ao Brasil, ao mesmo tempo percebemos um esforço recente de construção de uma representação que não se limite somente ao eixo Rio-São Paulo, ampliando a diversidade daquilo que poderíamos tentar caracterizar como uma produção brasileira. A partir desse processo de descentralização a equipe da UFMG se inseriu nesse importante e interessante fórum de discussões que tem se consolidado cada vez mais nacionalmente.

Ainda vemos no Brasil que a cenografia é muito vinculada ao domínio do teatro. Entretanto, percebe-se que outras áreas do conhecimento têm se relacionado com a cenografia enquanto um importante dispositivo e mesmo um procedimento na produção de espaços. O Barracão UFMG tem se mostrado

\footnotetext{
11 However, we should not assume that a process of sharing and learning from each other is a simple or straightforward matter; even if it seemed to be expressed as such in the 1975 catalogue, it is clear now that the scale and reach of $P Q$ means that it cannot (and should not) expect to bring about a homogenous view of performance design or a single community of practice. There is (and there needs to be) debate, challenge and disagreement about where the boundaries of performance design should be drawn and what the core values and principles of the practices within it are. The perspectives that different participants bring to these debates are informed by strikingly different sets of concerns arising from particular social, cultural and political conditions. On closer inspection, $P Q$ demonstrates that we cannot think of one singular community of practice but of many communities that intersect. (PŘíHODOVÁ; MCKINNEY; LOTKER, 2016, p.08).
} 
um possível exemplo disso, justamente porque tem operado em um registro em que o teatro pode ter a mesma relevância que a arquitetura, o design, as artes visuais e outros campos diversos no que tange à prática cenográfica. $E$ isso entra em consonância com as mudanças que têm caracterizado a $P Q$ enquanto um evento relevante na cena internacional.

\section{Considerações finais}

A experiência que tem sido desenvolvida pelo Barracão na UFMG tem se mostrado razoavelmente bem-sucedida e em constante consolidação dentro da universidade e na cidade. Aos poucos, as iniciativas propostas têm amadurecido, frutificado e encontrado resultados cuja reverberação em seu contexto imediato tem contribuído para a compreensão da cenografia enquanto campo do conhecimento. A busca por uma integração entre as dimensões do ensino, da pesquisa e da extensão através de atividades comuns tem se revelado uma ação relevante sobretudo porque consegue operar a Cenografia, um campo do saber e também do fazer, composto por vários saberes e fazeres, em diversos aspectos.

No contexto dessa produção do grupo de pesquisa Barracão UFMG, percebemos que a $P Q$ se tornou uma importante força motriz, na medida em que representa um incentivo ao desenvolvimento de trabalhos no âmbito do ensino e da extensão, bem como um fórum de questionamentos e discussões que abastecem as pesquisas no âmbito do grupo, sejam elas teóricas ou mesmo práticas. A aproximação sistemática com as questões levantadas ao longo das últimas edições da $P Q$ tem possibilitado uma melhor compreensão do processo de expansão da cenografia enquanto campo do conhecimento.

As práticas experimentadas no âmbito do Barracão, principalmente aquelas relacionadas às questões propostas pela PQ19, têm evidenciado uma mudança na noção de Cenografia. O que antes estava restrito ao campo das artes cênicas agora está presente em diversos outros tipos de even- to, como exposições, desfiles de moda, ações de marketing, dentre vários outros. ${ }^{12}$ Isso só corrobora a tese de que a Cenografia tem adquirido mais autonomia enquanto linguagem, tornando-se um campo especializado e independente, o que a abre para outras possibilidades diversas de manifestação. Essa diversificação, em contato com experiências ligadas aos modos ditos tradicionais, revigora essas práticas e promove ainda mais a diversidade e a investigação. A cenografia tem como particularidade a convergência de diversas disciplinas no seu fazer, que atuam na interseção de áreas, tornando-a bastante complexa. A PQ acaba por ter uma condição formativa importante assumindo seu lugar de norteador conceitual, local de trocas e fomento de conhecimentos e experiências, sempre em constante apuramento e transformação.

Nesse sentido, a $P Q$ ainda passa por um processo de transformação em que temos uma gradativa mudança do conceito de Cenografia para o de Performance Design. A edição de 2019 aprofundou-se ainda mais nessa perspectiva. Entretanto, essa ideia ainda não se encontra totalmente desenvolvida, sequer consolidada. Muito se discutiu ao longo das atividades de reflexão e discussão da $P Q$ sobre o que esse conceito vem a ser e, certamente, presenciamos nesta edição mais recente mais experimentos práticos que nos ajudaram a compreendê-lo melhor, em comparação com o que foi visto em 2015. Contudo, a presença de trabalhos que ainda operam no registro daquilo que tradicionalmente entendemos por cenografia nos leva a crer que estamos lidando com um conceito ainda em formação e com um amplo horizonte de discussão a ser explorado.

Parece haver, segundo a nossa visão, na raiz dessa problematização, uma reivindicação de autonomia daquilo que é denominado performance design, ou seja, ele estaria se tornando uma lingua-

12 Cohen (2007) aborda e discute a apropriação da cenografia por outros campos, cunhando a noção de cenografia aplicada, diferenciando esta da cenografia vinculada às artes cênicas e performáticas. 
gem independente. Porém, percebemos na prática, e o trabalho no âmbito do Barracão ajuda a ilustrar isso, que apesar de a cenografia estar se consolidando enquanto campo do conhecimento, sua autonomia enquanto procedimento e mesmo dispositivo, é relativa. A cenografia, ou mesmo o que tem se denominado performance design, nasce a partir de demandas específicas que dispõem as variáveis da equação de concepção de um determinado evento ao qual ela estará vinculada. Esse espaço da performance, esse cenário, está em relação a algo maior (como, por exemplo, a montagem de um espetáculo teatral), cujas demandas surgem a partir de diversos motivadores que caracterizam cada tipo de evento em suas especificidades. Ao que nos parece, essa relação de interdependência é que colabora para a compreensão da noção de cenografia, uma vez que, sem ela, possivelmente os trabalhos poderiam ser entendidos como pertencentes a outros campos das artes visuais, como a instalação.

Por fim, a reflexão aqui colocada ao apresentarmos a participação da UFMG na Mostra dos Estudantes da PQ19 nos mostrou como o envolvimento com esse evento tornou-se um fator de impacto na produção do Barracão UFMG. Isto se deu, como vimos ao longo desse artigo, ao percebermos que a Cenografia deixou de ser abordada apenas como um ofício, passando a ser encarada enquanto tema de pesquisa acadêmica e linguagem específica capaz de operar na produção de um espaço. Sua complexidade se dá enquanto lugar multidisciplinar, que permite congregar diversos saberes, fazeres e habilidades que se relacionam de modo complementar. Enquanto docentes, verificamos que os alunos que se interessaram pelo tema encontraram uma miríade de possibilidades de abordagens e puderam exercer um pensar criativo e um fazer reflexivo que em muito os ajudou na sua compreensão e no amadurecimento de suas ideias, fossem elas conceituais ou mesmo práticas.

\section{Referências}

COHEN, Miriam Aby. Cenografia brasileira século XXI: diálogos possíveis entre a prática e o ensino. 2007. 198 f. Dissertação (Mestrado em Artes) - Escola de Comunicação e Artes, Universidade de São Paulo, São Paulo, 2007. Disponível em: <http:// www.teses.usp.br/teses/disponiveis/27/27139/tde17102007-090756/>. Acesso em: 20 ago. 2019.

DIRETÓRIO DOS GRUPOS DE PESQUISA NO BRASIL. Barracão: Núcleo de Pesquisa e Experimentação em Cenografia e outras práticas espaciais cênico-performáticas. 2014. Disponível em: <http://dgp. cnpq.br/dgp/espelhogrupo/8430353857049429>. Acesso em: 30 out. 2019.

MONTEIRO, Cássia M. et al. Imagina [trans]forma [inter]ação. Rio de Janeiro: UFRJ, Escola de Belas Artes, 2019. 113 p.

PAIVA, Sonia (Org.). Brasil: labirintos compartilhados. Brasília: Laboratório Transdisciplinar de Cenografia, 2015. 208 p. II.

PŘíHODOVÁ, Barbora; MCKINNEY, Joslin; LOTKER, Sodja. The Prague Quadrennial of Performance Design and Space 2015. Theatre and Performance Design, v. 2, n. 1-2, p. 5-16, 2016.

REWA, Natalie. PQ11: a "still point of the turning world". Canadian Theatre Review, v. 152, p. 73-76, 2012a.

REWA, Natalie. The Prague Quadrennial: Repositioning design for performance. Australasian Drama Studies, n. 61, p. 131-155, 2012b.

ROCHA, Rosane Muniz. Umpanorama dotraje teatral brasileiro na Quadrienal de Praga (1967-2015). 591 f. Tese (Doutorado) - Programa de Pós-Graduação em Artes Cênicas - Escola de Comunicações e Artes / Universidade de São Paulo, São Paulo, 2016. 2 v.

Recebido: 30/08/2019

Aprovado: 26/02/2020 